\title{
L3, the tertiary language
}

Björn Hammarberg

Stockholm University

E-mail: ham@ling.su.se

Manuscript for:

Hammarberg, B. 2018. L3, the tertiary language. In Foreign Language Education in

Multilingual Classrooms, A. Bonnet \& P. Siemund (eds.), 127-150. Amsterdam/Philadelphia:

John Benjamins. 


\section{L3, the tertiary language}

\section{Introduction}

It is a well known fact that people who learn a new language often have experience of one or more other non-native languages already. In a school situation, this applies, for example, to students taking a second or further foreign language, but also to many minority or migrant children when they study their first foreign language in class. In traditional research on second language acquisition (SLA), no distinction is usually made between learners of their first nonnative language (the first L2) and those who go on to learn further languages. All are treated simply as second language learners. Up till recently, the first language (L1) was the only language that was taken into account as a potential source of cross-linguistic influence on the learning process, and any influence from other previously learned languages was usually ignored or thought to be insignificant. However, with the current growing interest in multilingualism, in society as well as in the individual, this view is changing. Within the past couple of decades, a rapidly developing body of research on so-called third language acquisition (TLA) has shown that the situation for a learner with prior experience of acquiring one or more non-native languages is different from that of a first-L2 learner in important respects. This means that the dimension of complexity in the learner's language background is now being taken into account, and what it involves is being investigated.

One aspect of this is the awareness that the L1 learner, the first-L2 learner and the learner of further languages are differently equipped for the task, which influences the learning process variably. Hufeisen expresses this in her Factor Model which she has developed in several works (1998, 2003, 2005, 2010, this volume) by specifying a number of linguistic and extralinguistic factors which guide the language learning process. When the learner proceeds 
in the course of time from the acquisition of the first language to the learning of a second language and then to the learning of a third language, new factors are added, so that the set of factors that come into play becomes increasingly complex. The new factors that apply when moving from learning the second to the third language are connected with the prior experience of an L2. They consist of foreign language specific factors (such as individual foreign language learning experiences and strategies, language interlanguage of previous languages, interlanguage of target language), and linguistic factors (knowledge of the prior L2, in addition to L1) (Hufeisen 2005: 38, cf. also 2010: 204). If the learner moves on to learn more languages, no further factors come into play. Those factors which guide the learning of the third language also apply to subsequent languages, although they will become increasingly developed and refined (Hufeisen 2010: 204-205). There is thus, according to this model, a qualitative difference between the learning of the first non-native language and any further languages, as represented by the different sets of governing factors that are involved.

Another aspect is that a richer repertoire of languages provides a more complex and variable pattern of cross-linguistic influence, especially the fact that influence may arise not only from an L1, but also from a prior L2. With more background languages, an issue in current research is the question under which conditions a particular language will influence the use and learning of the target language. Several such conditions have been proposed and their effects and interactions with each other are being studied (Falk \& Bardel 2010).

A further aspect is the potential benefit that a complex repertoire of languages provides for the learner in terms of greater linguistic resources and awareness (Cenoz 2003, 2013). This also implies possibilities to make systematic use of learners' multilingual background in foreign language teaching (see e.g. Neuner 2004).

This concern with complex linguistic backgrounds in language learning has led to a diversification of the concept of second language as it has usually been applied in SLA 
studies. Besides the established categories first and second language (L1, L2), the additional term third language or $L 3$ has come into use. In established usage in SLA studies, L1 refers to any native language, i.e. a language acquired from early infancy, and L2 refers to any nonnative language, i.e. a language added later. (The terms first and second language have lost their literal sense of language number one and two, due to the fact that a person may have more than one native and more than one non-native language.) What we can mean by L3 and how it relates to L1 and L2 is neither self-evident nor trivial, however. How we define and use these terms is important because the way in which we construe them reflects and affects our understanding of how multilingualism works and develops in the individual. The category $\mathrm{L} 3$, the relative newcomer in the terminology, is motivated by the need to deal with the complex language constellations that occur with the multilingual learner, and to distinguish this from a simple L1-L2 relation. This raises questions regarding the definition of L3 and its relationship with the learner's other languages in the process of language use and acquisition.

The term L3 has become quite established in research and in the general debate by now, and it seems reasonable to assume for the time being that it has come to stay. In TLA studies, the term is often being used in a simple way, as a label for language number three in a chronological order of acquisition. This tends to be the case especially in contexts where precisely three languages are at play, one L1, one previously learned L2 and the current target language, L3. But language use and acquisition by multilinguals, viewed in general, involves much more than that. There is often no strong reason to put a particular focus on language three in a multilingual speaker's repertoire, nor to limit the perspective to strictly sequential acquisition of languages over time. It is rather for methodological reasons that many investigators prefer to concentrate on trilingual settings; it produces a neat model situation with an L1, an already familiar L2 and another non-native language as the current target. But if we envisage a term that can represent a non-first non-native language more generally in 
relation to different degrees and histories of multilingualism and to different situations of language use and acquisition that occur in real life, then we need to define a concept of greater generality.

The present chapter aims to examine the construct of L3 in the context of the speaker's multilingual repertoire and language learning, and to outline the basis for an adequate use of the term L3. I first touch upon the wide occurrence of bi- and multilingualism in the world of today, especially as it is promoted by globalization and modern communication technology, and argue that multilingualism should be regarded as the normal form of linguistic competence that develops in human speakers. Secondly, I discuss the mutual connection between the developing linguistic repertoire and the process of language use and acquisition in specific situations in time. Thirdly, I focus on how to define and characterize the concept of L3 and point out how this category differs from those of the speaker's other languages. Fourthly, I consider some recent research that has explored the various factors that may determine which language will dominate as a source language for cross-linguistic influence when acquiring an L3. From an educational point of view, this research has implications for understanding the potential significance of a multilingual learner's various background languages and making use of this in language teaching.

\section{The multilingual context}

Bi- and multilingualism is one characteristic feature of human life. ${ }^{1}$ Linguists working in this area are widely of the opinion that bi- or multilingualism is more common in the world's

\footnotetext{
${ }^{1}$ The way in which the terms bi- and multilingualism are defined varies somewhat in the literature, foregrounding either the social or the individual domain, either use or knowledge, sometimes requiring highlevel proficiency in each language or early simultaneous acquisition. Sometimes the terms bi- and multilingualism are treated as synonyms, or one term is used for both. Sometimes the term plurilingualism is used instead of individual multilingualism. Here I will follow one common terminological practice and define individual mono-, bi- and multilingualism as knowledge of one, two and three or more languages, respectively,
} 
population than monolingualism. It is found to be increasing in the modern society with its globalization, mobility and fast communication (see Aronin \& Singleton 2012).

Multilingualism is part of our personal development. In the course of life, people tend to pick up knowledge of languages with which they get into active contact. This can take place naturally in daily life, or through organized study. It is obvious that all humans have the potential of acquiring several languages. This indicates that multilingualism is natural to human speakers and an integral part of the human language faculty. It can be argued that multilingualism as it develops over the lifespan is the normal form of language competence. This is a break with a traditional attitude in Western societies to see monolingualism as the normal state and regard the knowledge of additional languages as special, extended cases. Adult monolingualism, where it occurs, is rather the case that needs to be explained (see Hammarberg 2012).

Individual multilingualism develops for different reasons, in different kinds of environments, and in different forms. In some parts of the world, such as for example Papua New Guinea or many parts of Africa, local linguistic populations live in close contact with each other, and the alternate use of several languages is a regular part of daily life. With the process of modernization comes the need also to learn national and international languages, which in a short perspective increases people's multilingual repertoires (but in the long run may lead to the abandonment of local languages and thus the reduction of multilingualism). Contacts with other countries of course motivate language learning. In this respect the European scene is characteristic with its multitude of states, each with its configuration of languages, existing in close contact and communication with one another, while English also increasingly functions as a lingua franca. (On the role of English in Europe, cf. Cenoz \& Jessner 2000; House 2008). Bi- and multilingual countries create a complex language multilingualism, and the terms do not presuppose a certain level or type of proficiency in each language. 
situation especially for the speakers of the minority populations, who need to handle the language of the majority as well for various public functions. Language diversity is a particularly striking phenomenon in bi- and multilingual urban communities, where it is connected with many aspects of demographic and cultural structure, the city's linguistic landscape, and policy regarding public services, education, and so forth (Boix-Fuster 2015; Extra 2015; Extra \& Gorter 2001, 2008; Extra \& Yağmur 2004). In the multilingual and multicultural youth environments which have arisen in European larger cities as an effect of migration, the coexistence of different languages is a given reality, and the development of specific, identity-creating varieties besides the standard language is a consequence (Bardel, Falk \& Lindqvist 2013; Källström \& Lindberg 2011; Quist \& Svendsen 2010).

Foreign language learning in school settings can be seen in its relationship with the various cases of language acquisition that take place for "natural" reasons and under "natural" conditions. The distinction that is often made between (instructed) foreign language learning and (spontaneous) second language acquisition is indeed well motivated, in view of the differences both in ways of learning and in type of results. ${ }^{2}$ Yet, although foreign language learning has to proceed (typically) in the absence of a real target language environment and learners thereby tend to get fewer opportunities of realistic interaction and natural reasons to communicate and have to rely more on metalinguistic learning, there is a basic connection between foreign language learning and uninstructed language acquisition in "natural" environments. In both cases, the acquaintance with different languages provides comparative language experience and furthers linguistic awareness. During our lifespan, we develop a

\footnotetext{
${ }^{2}$ The use of the terms language acquisition and language learning varies in the literature. A distinction is upheld in contexts where it is important and focused on. Thus (uninstructed) second language acquisition taking place in the target language environment is contrasted with (instructed) foreign language learning, usually outside the target language environment. In another approach, first language acquisition is contrasted with second language learning (e.g. Paradis 2004 in his neurolinguistic theory of bilingualism). In contexts where such distinctions are not in focus, acquisition and learning tend to be used as synonyms, or one term is used in a broader sense covering both, for example in the names of the subject fields second language acquisition (SLA) and third language acquisition (TLA). In the present chapter, I use the terms acquisition and learning interchangeably, except when referring to authors who are using the finer distinction.
} 
stock, or repertoire, of linguistic knowledge, experience and skills, acquired in a variety of ways and contexts. There is no reason to assume that learners who learn foreign languages through organized study could not draw on this wider linguistic resource (cf. Hufeisen 2010: 205).

\section{The language repertoire and situations of language use}

A person's multilingual development involves the buildup of a repertoire of languages. This is an ongoing process which includes the adding of knowledge of new languages over time, but also other aspects such as:

- Changes in level of proficiency in the respective languages: gradual growth, also attrition

- Changes in depth and type of knowledge, familiarity with variation (dialects, sociolects, genres, styles, trends etc.), familiarity with the cultural context of each language and the social norms governing its use

- Comparative knowledge of different languages

- Metalinguistic awareness

- Experience of language use in situations

- Experience and skills in learning languages; strategic skills in using and acquiring language

- Attitudes, affective relations to specific languages

The notion of a linguistic repertoire was introduced in the sociolinguistic work by John Gumperz in the 1960s and has since then played an important role in sociolinguistics. Gumperz (1972: 20) defines it as "the totality of linguistic resources (i.e. including both 
invariant forms and variables) available to members of particular communities". Whereas Gumperz (and later sociolinguistic work) stresses the social side, the concept of a repertoire has also been applied with a focus on the language knowledge of individuals (Blommaert \& Backus 2013). I will deal with this latter aspect here.

It has been emphasized by many that a person's knowledge of languages forms a coherent whole, rather than separate competences in each language. Cook (1992) refers to this holistic knowledge as a multicompetence. According to Paradis $(1981,2004)$ the speaker's languages are assumed to be represented in the mind as subsets within the same larger cognitive system. One much-debated issue is whether this system contains separate lexicons for each language, or one common lexicon. Predominant research today points to the conclusion that words of different languages are stored in a common lexicon, so that they are simultaneously accessible for searching in the memory (de Bot 2004). In this way words from more than one language can compete for activation both in perception and production of speech (de Bot 2004: 23), which may give rise to cross-linguistic transfer.

A central aspect of a language repertoire is that it keeps developing over time. This feature is an essential part of the perspective on language represented by approaches such as Dynamic Systems Theory (DST; Verspoor et al. 2011), Complexity Theory (see Larsen-Freeman \& Cameron 2008) and the view of language as a Complex Adaptive System (Ellis \& LarsenFreeman 2009). Language and language use is understood here as a developing complex system, which is variable and continuously changing and contains interacting elements and forces. Complex systems contain subsystems and are themselves part of a larger system. Thus, for example, a person's repertoire of languages constitutes a complex system, and so do the various languages forming the repertoire; similarly, a speech situation forms a complex system, as well as the many interacting subsystems that are involved in the situation. This view on language assumes a usage-based approach (cf. Langacker 1999; Bybee \& Beckner 
2012), according to which development is driven by use of the system. Language is seen as an adaptive system which is socially situated: it develops through the user's interaction with the social environment, especially with other language users, as well as through internal selforganization. This system and its parts can be studied over shorter or longer periods or at a given point in time.

A language in the repertoire becomes an L1 or an L2, depending on the individual's stage of cognitive maturity at the time when it is internalized and stored in memory. An L1, or native language, is acquired from early infancy during a period when the child learns the basics of linguistic interacting and first establishes linguistic categories, structural patterns and rules of use. An L2, or non-native language, is a language added after this period, when the initial process of language acquisition has taken place and the speaker - as older child, adolescent or adult - has become cognitively more mature. Paradis $(2004,2008,2009)$, in his neurolinguistic theory of bilingualism, posits two distinct mechanisms for, what he terms, the acquisition of implicit linguistic competence in L1 and the learning of explicit metalinguistic knowledge in L2. According to Paradis (e.g. 2008: 343), an L1 is acquired incidentally, stored implicitly, used automatically and sustained by procedural memory, whereas an L2 is learned consciously, stored explicitly, consciouscly controlled when used, and sustained by declarative memory. L1 and L2 also involve different parts of the brain. Paradis emphasizes, however, that the explicit knowledge of an L2 may become automatized when the language is used in practice, i.e. successively replaced by implicit competence as the conscious learning process is gradually taken over by unconscious, incidental acquisition.

The transition from the period of implicit acquisition to that of explicit learning takes place gradually in the young child. Thus if a child has encountered a new language at a certain age within this transition period, it may be difficult to tell categorically whether it should be considered an L1 or an L2. It may be L1-like in some respects and L2-like in others. 
Researchers differ as to the timing of this process. Paradis (2008) places the end of the L1 acquisition period at about age five. In investigating child SLA, McLaughlin (1984) chooses the third birthday as a practical cutoff point between first and second language acquisition. ${ }^{3}$ Meisel (2011), reviewing research on neural maturation and age, finds that changes in the direction from L1-type to L2-type processing seem to take place at least up to age seven, with certain crucial changes around age four. Hyltenstam and Abrahamsson (2003), investigating age of onset and ultimate attainment, report effects that appear to indicate that the child's capacity for L1-type acquisition starts to decrease successively already shortly after birth. There is thus reason to interpret the L1/L2 distinction cautiously in the case of languages with an onset within this transition period. On the other hand, when dealing with a language acquired from early infancy or one learned in late childhood, adolescence or adulthood, the L1/L2 distinction will be clear-cut. The term primary language is sometimes used in linguistics as equal to a native language, or L1. Given that L2s are languages which presuppose a period of basic language acquisition when one or more L1s have been established, L2s can be designated as secondary languages. ${ }^{4}$ Certain observable facts, for example that L2s in contrast to L1s are subject to fossilization, and that cross-linguistic transfer usually goes more from an L1 to an L2 than vice versa, are indicators of a cognitive difference between L1s and L2s in the mature speaker.

When considered in its entirety, a multilingual repertoire comprises languages of different prominence for the speaker. Some languages may be used on a regular basis, others more rarely. The speaker' knowledge of the languages will vary in level of proficiency, or be different in kind. In some cases, the proficiency is limited to reading and/or listening comprehension, or to familiarity with terminology in some subject area. The knowledge of some languages may be largely metalinguistic in nature, consisting of knowledge about the

\footnotetext{
${ }^{3}$ See note 2 .

${ }^{4}$ The term secondary language is sometimes used in the literature for a non-native language, notably in the seminal work on language contact by Weinreich (1953: 14).
} 
language. In some cases, the comprehension of a language will be aided by familiarity with another language which is closely related and very similar to the target language. For example, close languages like Danish-Norwegian-Swedish or Bosnian-Croatian-Serbian will all be comprehensible to a speaker who knows one of them well. Thus the knowledge of one language provides comprehension of other, close languages as a bonus, so to speak. Likewise, for example, Italian-Spanish, Dutch-German, English-German or German-Swedish will support each other to a considerable extent. Familiarity with the "international" (Latin and Greek based) vocabulary which occurs widely in European languages will have a similar effect. ${ }^{5}$ Blommaert \& Backus (2013: 17) distinguish broadly between several degrees in the learning of languages: 'comprehensive' language learning, leading to a "maximal” set of resources in the respective languages, 'specialized' language learning which produces various kinds of more restricted or partial forms of linguistic knowledge and skills, and 'encounters' with language which refers to learning "very small bits of language" such as single words, slang expressions or various fragments. Blommaert and Backus even count the mere ability to recognize and identify languages as parts of the repertoire. In a description of one highly multilingual speaker's repertoire, they sort the languages into four large categories: maximum, partial, minimal and recognizing competence.

A person's repertoire of languages is therefore a complicated thing to capture in total. It is not immediately obvious how it can be adequately accounted for in connection with language learning. Should all languages, whatever the learner's knowledge of them is, be taken into consideration as potentially interacting languages in a learning situation? Apparently the answer is yes. Current studies on cases of L3 acquisition tend to limit themselves to constellations of languages with some recognized standing in the learner's repertoire, and to leave aside any potential influence from various kinds of minimal or specialized knowledge in

\footnotetext{
${ }^{5}$ On the matter of intercomprehension of similar languages, cf. e.g. Hufeisen \& Marx 2007; Klein \& Rutke 2004; for Scandinavian languages Delsing \& Lundin Åkesson 2005.
} 
other languages. This will certainly make a study more manageable or concentrate the focus on specific research questions, and therefore often be preferable. On the other hand, it is obvious that minimal or specialized knowledge of background languages sometimes does have an influence, even if we actually know rather little about this at present, in the absence of systematic research on this issue. In dealing with language learning in multilinguals, we cannot simply exclude potential influence - and support - from various minimal or specialized linguistic background knowledge. We then need to use terms such as L1, L2 and L3 in such a way that they do not preclude such cases of cross-linguistic influence.

As I mentioned, a linguistic repertoire is a continuously developing system. If we adopt a usage-based theory of language, language acquisition is assumed to be driven by use of the language in specific situations. Concrete communicative events thus shape the buildup of the repertoire over time. Conversely, the process of language use and acquisition in such situations is dependent on the current state of the repertoire with its complex linguistic contents. Hammarberg (in press) discusses the interconnection between the developing repertoire and language use in situations and distinguishes two major points of view that are seen to occur regularly in SLA and TLA research. He characterizes them as a macro and a micro time perspective. The former constitutes a long-term view on languages and learning. It deals with the speaker's multilingual competence and practices, how this develops and changes over time, the stages and sequences of development, etc. This includes how the the languages contained in the repertoire are structured, used and mastered, and how this develops over time. The latter, short-term perspective deals with states and processes in situations. It has its focus on the speaker's options, activity and linguistic products on specific occasions when the language is being used, and on the conditions and factors that govern the acquisition process in such situations. While the interdependence between the repertoire and the specific 
events of language use is crucial, placing the focus on one or the other will involve different issues.

One aspect in the macro time perspective is the chronology in which the languages occur and develop. One very common practice in connection with multilingualism and TLA is to sort the languages according to a chronology of onsets, i.e. in the order in which the speaker has started acquiring them. The languages are then designated by numbers in a series: L1, L2, L3, L4, L5, etc. This sorts the speaker's languages into a simple historical schema and is applicable to languages that can be placed in a clear linear order. But it is connected with some problems that should be noted. First, the terms L1 and L2 are being used in a different sense here than the standard SLA sense of any native versus any non-native language, which makes these terms ambiguous. This usage also restricts the term L3 to meaning the third language in onset order which, as we shall see, is problematic. Second, a linear order presupposes a strictly sequential order of acquisition, which is often not the case in real life; languages may be acquired simultaneously, or in an alternating fashion where the order of onset may be hard to determine. Third, the numbering depends on which languages should be counted, which is a problem in itself, as we saw above. The number series may thus be dependent on an uncertain conception of which languages should be included. Fourth, one should be aware that the chronological numbers relate to the development of the repertoire over time, not to the roles that the languages have in the acquisition process during situations of use, a distinction which does not always seem to be observed in the literature. For these reasons, it seems wise to use the linear chronological numbering of languages restrictively, with the problems mentioned here in mind.

Whereas a chronology of onsets is a simple, or simplifying, way of representing a person's language history, a chronology of use is much more complex and complicated to account for. Yet the chronology of use is more representative of the development of the repertoire. Of 
course languages are not only introduced at some point in time, they keep developing over the lifespan, growing, attriting if not used, changing function for the speaker and thereby changing the ways they are acquired and the frequency of use. At any given point in time, a person's repertoire forms a complex of coexisting languages. They develop along with each other and change their pattern of prominence or dominance in relation to each other. What a person's language history is about is the development of this dynamic complex system. The acquisition process that takes place when a language is being used will draw on the current state of this repertoire at the time of use.

A central concern in the micro time perspective is to explore the circumstances and conditions that govern the process of acquisition during events of language use. The situation that arises when a language is being used forms a complex system in itself which contains the use of the current target language as a part. This system will vary depending, inter alia, on the content of the linguistic repertoire which is available to the speaker at the time. A range of extralinguistic factors also come into play and interact to influence and guide the learning process. These factors also vary with the current state of the repertoire. Hufeisen's Factor Model (see Section 1 above and Hufeisen's chapter in this volume) outlines the set of such linguistic and other factors and shows how it gets successively more complex if a speaker proceeds in sequential order from acquiring a first language (L1) to learning a second language (L2) and then a third language (L3). The model thus combines a micro and a macro time perspective by comparing the conditions that govern acquisitional processes at different stages of development of the learner's linguistic repertoire. In particular, it demonstrates the qualitative difference between being faced with an L2 for the first time and continuing with one or more other non-native languages thereafter.

The Factor Model has its focus on the conditioning factors. Their effects, on the other hand, get manifested in the processes of acquisition that take place in the actual situations of 
language use. Hammarberg (in press) proposes a variable model of such events as they apply to a potentially multilingual user/learner. The processes of use and acquisition take place as the individual interacts with his/her current linguistic environment, receiving and/or producing utterances in context. As in Hufeisen's model, a factor approach is adopted here. The model is designed as a template with variable realizations from time to time, depending on the language user's state of mono-, bi- or multilingual development. Figure 1 shows the model as applied to an L3 user (allowing for one or more L1s and one or more prior L2s).

\section{Language user/learner}

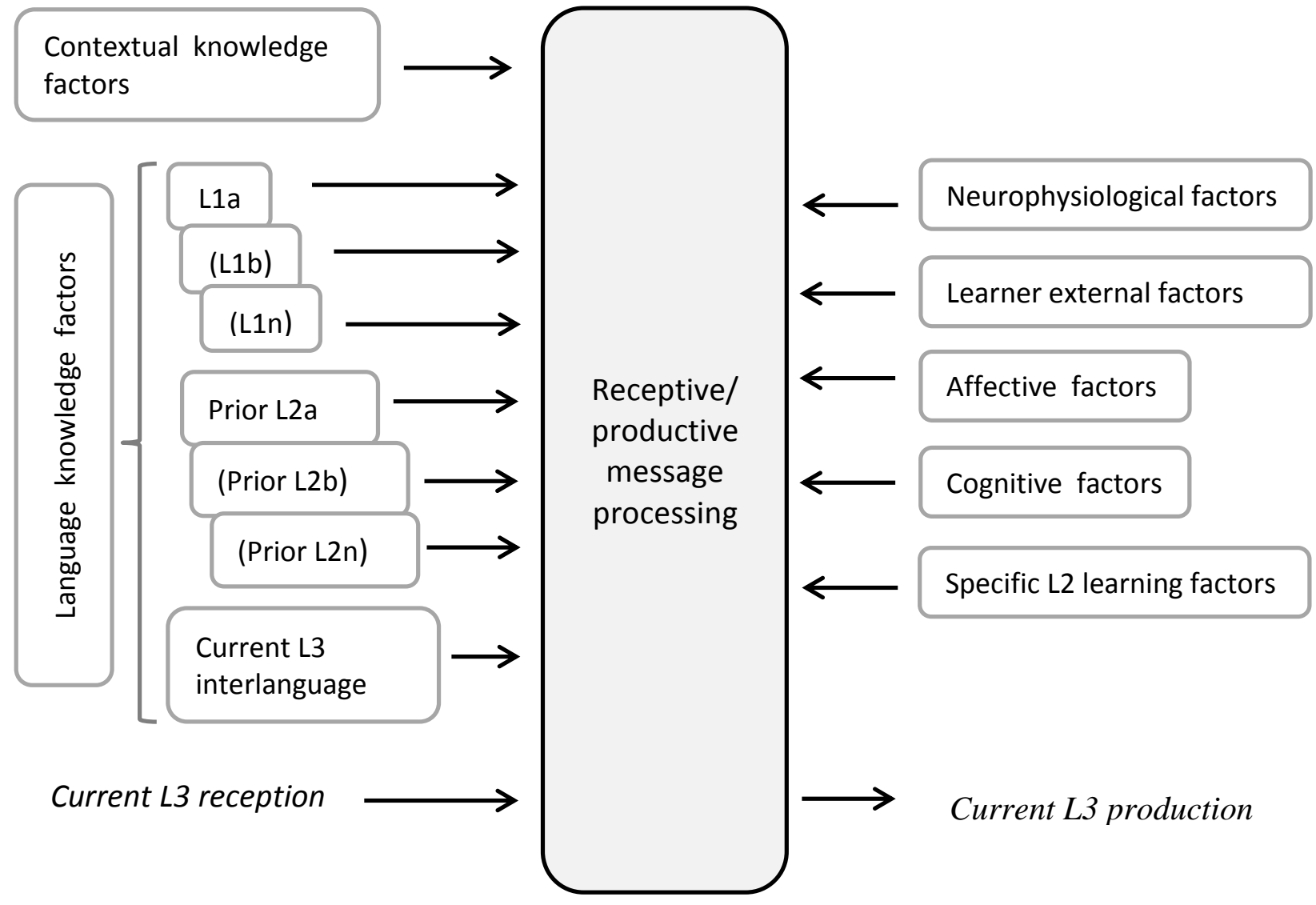

Figure 1. L3 use (non-native language use by a multilingual speaker). From Hammarberg (in press). 
The model contains as its central part a mechanism for receptive and productive message processing which receives and produces utterances in the currently used language and is guided by a set of conditioning factors.

The boxes on the left side represent the user's contextual and linguistic knowledge. The contextual knowledge factors comprise the awareness of the preceding discourse, the understanding of the situation, and the encyclopaedic "knowledge of the world" pertinent to the situation. The language knowledge factors are the user's current state of knowledge of one or more L1s, one or more already familiar L2s, and the current L3 interlanguage as developed so far; the parentheses indicate "if occurring".

On the right side are several other individually related factors. For the time being, these types of factors are assumed to be essentially those of Hufeisen's Factor Model, summarized here from Hufeisen $(2005,2010)$, with the proviso that they will still have to be further elaborated and be open to revisions.

These various factors will apply only to the extent that they are applicable to the speaker's state of linguistic development. Thus, more reduced versions of the model will apply to an L1-only speaker or to a learner of a first L2 (Hammarberg, in press). On the other hand, the model takes the whole contents of the current repertoire into account at every stage to which it is applied: studied languages as well as languages acquired informally, languages at different levels of proficiency, even minor or partial knowledge and different types of knowledge of a language. Although the speaker/listener/learner is normally focused on the language that is currently in use (the selected language in the sense of Green 1986), his/her knowledge of the other languages that coexist in the repertoire at the time (the background languages) is in principle available for activation in the situation to a greater or lesser extent. In practice, most of this co-activation will involve one or more "major" languages in the speaker's repertoire. I 
will come back below to the question of which language(s) will be most likely to get activated.

\section{Defining $L 3$ as a tertiary language}

How is the category of L3 to be defined and characterized? In view of what has been said above, it is a matter of defining a concept which represents a non-first non-native language that has the role of selected language for a multilingual speaker a situation of language use and acquisition. For a learner this means the current target language. We require that this concept should be cognitively grounded and compatible with how the terms L1 and L2 are commonly used in the field of SLA, i.e. as any native and any non-native language, respectively. It should be applicable to speakers with various numbers of background languages, and the speaker's knowledge of these languages may be at various levels of proficiency and may be of various types.

A definition of L3 along these lines is the following, quoted here from Hammarberg (2010: 97):

In dealing with the linguistic situation of a multilingual, the term third language (L3) refers to a non-native language which is currently being used or acquired in a situation where the person already has knowledge of one or more L2s in addition to one or more L1s.

[Italics in original.]

Defined in this way, the concept of L3 is not based on the counting of languages; the current L3 is not necessarily "number three" in acquisition order. Rather, it rests on the cognitive 
distinction between L1 and L2 as used in SLA research (cf. Hammarberg 2014). Any knowledge of L1s and L2s can be taken into consideration as linguistic background knowledge. The crucial point is that the category of L3 is situation-related. That is, an L3 is identified in relation to a given situation of language use. Whereas L1s and L2s are languages in the repertoire which are (more or less) known to the speaker in the given situation, the nonnative language used in the situation becomes the L3. L3 is thus a situationally defined special case of an L2, special in its role of constituting the current target language in a multilingual setting. Thus the concept of L3 does not contrast with the concept of L2, but with that of prior L2 (one or more) in the given situation.

It follows that an L3 learner is also, in a wider sense, an L2 learner. In traditional SLA usage where no distinction is made between a learner of a first L2 and one who learns further languages, all are referred to as L2 learners. The present definition of L3 is compatible with this, which has practical advantages. There are of course many topics in the field of SLA where the complexity of the learner's language background is not an issue. In such cases, it serves its purpose to speak of even multilingual learners as L2 learners, without going into the L2/L3 distinction. The traditional SLA usage causes no problems here. The novel perspective introduced with TLA research is to focus on the dimension of complexity in the linguistic background and distinguish an L3 learner from a first-time L2 learner. But clearly this is not an important aspect in every SLA context. Thus the same multilingual learners may either be defined widely as L2 learners or specifically as L3 learners, depending on what the topic is about.

L3s have been characterized as tertiary languages (German: Tertiärsprachen). This term was introduced in the literature in the 1990s to designate a second or further foreign language (see Hufeisen \& Lindemann 1998). It is being frequently used especially in German TLA research and pedagogy when dealing with the learning and teaching of a second or further 
foreign language in school settings, for example referring to the frequent case in many countries when German and other languages are learned as a subsequent foreign language after English. The tertiary language then corresponds to the third level of Hufeisen's Factor Model.

The notion of tertiary languages fits in well with the definition of L3 that we are discussing here and the wider perspective on multilingualism on which this definition is based. As mentioned above, an L2 can be called secondary because it presupposes a period of acquisition of an L1 (a primary language), and the first-L2 learner has L1 as background language. In a multilingual setting, a non-native target language (L3) presupposes both L1 and L2 background knowledge and is in this sense tertiary in relation to these primary and secondary languages. Hammarberg (2010) has argued that it might be a good choice to avoid the common terms "first", "second" and "third" language altogether because of the problematic association with the literal sense of number one, two and three in chronological succession, and instead read the abbreviations L1, L2 and L3 as primary, secondary and tertiary language, respectively.

\section{L3 and the background languages}

In a strictly bilingual situation, where a learner has one L1 and the target language as the only L2, only the L1 is available for cross-linguistic influence on the learner language. But in a multilingual situation, there are different background languages which potentially may have an influence on the development of the L3. It is well attested in TLA research that both L1s and L2s may become activated regularly and thus become sources of transfer. Exploring the patterns of such cross-linguistic influence and how they arise in multilingual cases has 
become one of the key areas in the study of TLA. Although it is clear that background languages may become activated both in comprehension and in production, the most comprehensive research on multilingual cases has been done in the area of learner production.

In a multilingual situation, what will cause a certain background language to become activated rather than another? A number of causing factors have been identified in the literature. Williams \& Hammarberg $(1998,2009)$ propose that four interacting factors determine which background language will most often become co-activated in L3 production:

- recency, i.e. the extent to which the learner has used the language recently

- the learner's level of proficiency in the background language

- the degree of typological similarity between the background language and the L3

- L2 status, i.e. if the background language is an L2 for the learner

The hypothesis is that the language that reaches the highest total score on these scales is the one which the learner will activate most often. Other contributing factors have also been suggested, such as if the language has been acquired in natural situations (Ringbom 1987: 113), if the language has been used actively (Heine 2002), at what age it has been acquired (Cenoz 2001), and the learner's emotional attitude towards activating a certain language (Hammarberg \& Williams 2009).

The factor recency has to do with how the level of activation of a language, and thereby the ease of using it, is influenced by its recent and frequent use. Green $(1986,1998)$ distinguishes three different states of activation of a language: selected (i.e. the language chosen to use), active (i.e. present in the memory without being selected, and capable of taking part in the speech process) and dormant (i.e. known to the speaker but without influence in the situation). At any specific point in time, a language is assumed to have a certain default level of 
activation. Repeated use of the language will raise its level and thereby its capability of becoming activated in the situation. By contrast, the level of activation will decrease if the language is not used for a long time. If this is the case, the speaker's access to a background language in memory should be influenced by a factor of recency of use.

Since high proficiency in a language makes it easier to use, a background language which the speaker masters well has an advantage as a potential source of transfer. However, this is somewhat more complicated. It has been shown that even a language at an elementary level can become activated and cause transfer in situations where L3 too is at a low level (De Angelis 2005; Bardel \& Lindqvist 2007). A finding is also that lexical transfer at elementary stages of L3 tends to affect the formal shape of words, whereas transfer at advanced stages tends to be semantic in nature (Ringbom 1987; Lindqvist 2010). The proficiency factor is also reflected in the fact that transfer is generally more frequent at lower stages of L3 development where the lack of expressive resources in L3 more often causes a background language to become activated.

Cross-linguistic typological similarity is the factor which has most often attracted attention in the literature. ${ }^{6}$ Many studies have shown that the relative similarity between the respective background languages and L3 is a strong factor which favours the closer language as a source of transfer. See especially Ringbom's (2007) thorough treatment of the factor cross-linguistic similarity in foreign language learning. However, similarity between languages is not a clearcut concept. It has been defined in different ways in different studies. A typological comparison of languages is primarily based on specific elements or structural features which are alike or differ between languages, and in that connection larger areas of the languages may also be more or less similar. Historical-genetic relatedness has also often been referred to as an indication of cross-linguistic similarity. However, even though this relatedness usually

\footnotetext{
${ }^{6}$ This factor is often referred to by the shorthand term typology, which is then to be understood as the degree of cross-linguistic typological similarity.
} 
also entails more or less far-reaching typological similarities, typological similarity cannot be predicted categorically on genetic grounds; historically related languages may be similar in some parts and different in others. It should be noted that historical relatedness, unlike specific typological similarities, primarily concerns whole languages. There is also a psychological aspect of similarity. It has been argued that the psychologically relevant criterion is the similarity or dissimilarity that the learner perceives or assumes, the so-called psychotypology (Kellerman 1983), rather than the factual typological (dis)similarity. Kellerman found in studies of learners' transfer behaviour in L2 (Kellerman 1977, 1978) that there was a tendency to avoid transfer from L1 in cases where the L1 structure was perceived to be "irregular" or "not transparent" or "marked", even though the languages were actually similar on the points in question. He coined the term psychotypology for 'the learner's perception of language distance" (Kellerman 1983: 114, italics in original). However, this kind of typological relation which is based on learner intuitions may be difficult to predict with any certainty, so in practice most studies have relied on objective typological facts in order to judge cross-linguistic similarity, or simply on the degree of historical relatedness.

The factor 22 status, that is the notion that a background L2 has a special reason to become activated in $\mathrm{L} 3$ production rather than an L1, has attracted much interest in recent TLA research. This notion goes against the traditional belief in SLA studies that L1 is the main, if not the only source of cross-linguistic influence on the learner language. The hypothesis that L2 status is a major influencing factor along with the other factors mentioned above was proposed by Williams \& Hammarberg (1998). The possible existence of an L2 effect had also been put forward earlier by Meisel (1983: 17-18) who, however, did not pursue the idea. An L2 status effect has been demonstrated in different areas of the language: lexicon (De Angelis 2005; Falk 2015; Lindqvist \& Falk 2014; Williams \& Hammarberg 1998, 2009); syntax (Bardel \& Falk 2007; Falk \& Bardel 2010, 2011; Lindqvist \& Falk 2014; Sánchez 2011); 
phonetics and phonology (Hammarberg \& Hammarberg 2009; Llama, Cardoso \& Collins 2010; Wrembel 2010).

Explanations for the L2 status factor have been proposed along various lines. Williams \& Hammarberg (1998: 323, 2009: 63) suggested a couple of possible reasons: (i) a different acquisition mechanism for L2s as opposed to L1s, and hence a reactivation of the L2 type mechanism in L3 acquisition, and (ii) a desire to suppress L1 as being inherently "nonforeign" and to rely rather on another "foreign" language as a strategy to approach the L3.

The first explanation is in line with Paradis' distinction between two separate neurocognitive mechanisms for L1 and L2 (see above). This has been pointed out by Bardel \& Falk (2012) who examine the L2 status factor from the point of view of Paradis' (2009) declarative/procedural distinction. Since both the current L3 and prior L2s are non-native languages, they show a neurolinguistic affinity with one another which they do not share with native languages. There are also other respects in which late-learned, non-native languages are similar; Bardel \& Falk (2012: 68) summarize this in the following way:

[...] the L2 status factor is an outcome of the higher degree of similarity between L2 and L3 than between L1 and L3, regarding age of onset, outcome, learning situation, degree of metalinguistic knowledge, learning strategies and degree of awareness in the process of language appropriation.

The four main factors mentioned above have all been found to play a role in favouring the activation of a background language. But to determine their relative strength and the degree of impact they have in relation to each other has become an issue of debate in recent TLA research. Since they are not dependent on each other, different factors may either support or counteract each other which means that different factors may, but do not have to favour the 
same background language as a transfer source. Several researchers have chosen to compare the effect of typology and L2 status in investigations, with conflicting results. In some cases the typology factor has turned out to dominate, e.g. Ó Laoire \& Singleton (2009), Rothman (2010, 2011), Rothman \& Cabrelli Amaro (2010). In other investigations the L2 status factor has been decisive, e.g. Bardel \& Falk (2007), Falk \& Bardel (2011), Llama, Cardoso \& Collins (2010), Sánchez (2011). Taken together, the results do not indicate that the relative strength of the typology and L2 status factors can be determined on a general basis. There are also complications connected with comparing the two factors. Whereas languages can be more or less close to one another, and hence typological similarity is a gradual phenomenon, the question of L1 or L2 status for a language is a categorical choice. It can therefore be expected that the typology factor will have a greater impact in the case of background languages which differ more in their distance to L3 than when the distance is more even, and that this will affect the strength relation between the typology and L2 status factors in a given constellation of languages. It is still unclear, however, how great this difference in language distance has to be for the typology factor to dominate. It is also somewhat problematic if two factors such as typology and L2 status are compared in isolation without other potentially influencing factors such as recency and proficiency being taken into account. There is still little research on the relative impact of these latter factors.

When teaching an L3, it may be of interest to judge the possible supportive role of the learner's various background languages and to look for reasons why a certain language (a previously studied foreign language, a certain minority or heritage language) may have a potential to influence or guide the learning of the L3. It may then be relevant to consider languages not only because they are available to the learner, but also to evaluate them by the properties that may play a role (a language which is typologically similar to the L3, one which 
the learner knows very well, one which the learner is using much, one by virtue of its being an L2, etc.).

\section{Summary and conclusion}

The awareness that many language learners already possess knowledge and learning experience of one or more other non-native languages has led to a diversification of the concept of second language. Exploring the influence of complex language backgrounds on language learning has become an area of interest in language acquisition research, and in language teaching the possibilities of making use of learners' prior knowledge of other second languages as a resource has attracted attention. This focus on language learning in multilingual settings has necessitated a term for a target language in situations where the learner has some prior knowledge of one or more other L2s. Such a language has come to be termed third language or L3.

I have argued in the present chapter that, rather than simplistically regarding L3 as the learner's "third" language, certain wider aspects of the complex phenomenon of multilingualism need to be taken into account if the concept of L3 is to be defined and used in an adequate way.

To this end, a definition of L3 should meet certain requirements. This concept should be compatible with the concepts L1 and L2 as these are commonly used in SLA research. It should be cognitively grounded rather than being based on the counting of languages acquired by the learner. It should be compatible with the nature of a learner's developing linguistic repertoire. It should be applicable to speakers with various numbers of background languages, and the speaker's knowledge of these languages may be at various levels of proficiency and 
may be of various types. It should not be restricted to sequential learning of languages or depending on the chronology of onset of learning the languages; rather, it should recognize simultaneous learning and concurrent development of different languages in the learner's repertoire.

The concept of L3 that I speak for here has certain essential characteristics. Crucially, whereas the terms L1 and L2 refer to languages with a role both in the learner's stored linguistic repertoire and in the specific situations of language use, L3 as the multilingual learner's current target language is a relevant concept only in a concrete situation of use, and not in the stored repertoire. The L3, being a non-native language, is an L2 that assumes the role of target language in the situation of use, hence a situationally defined special case of an L2. The category L3 does not contrast with the category L2, but with the coexisting background L2(s) in the situation.

In the literature, the term L3 is often used indiscriminately both as a multilingual learner's current target language and as the third term in a linear chronological series of onset of acquisition: L1, L2, L3, (L4, L5, ...). The two uses are obviously based on different defining criteria and reflect basically different conceptions of multilingual development. I have commented above on the problematic aspects of the latter practice. Our topic here has been discussing the basis for defining L3 in the former sense.

One central aspect of dealing with multilingual settings for language learning has been the exploration of the influence that various forms of complex language backgrounds have on learning the target language. The study of the various factors which condition such influence helps us understand why an L3 is likely to be more susceptible to influence from certain background languages than from others. From an educational point of view, this has implications for the possibility to make use of multilingual learners' prior linguistic experience as a resource in language teaching. 
L3s have been characterized as tertiary languages since they presuppose both some L1 (primary language) and some L2 (secondary language, presupposing the acquisition of some L1) as background languages. The expression tertiary language has attained a certain currency in the field of TLA. It seems to me that primary, secondary and tertiary language are better characterizing terms than first, second and third language. They have the merit of associating to a cognitive hierarchy and avoiding the association with a rigid chronology of three languages. The terms first, second and third language are certainly very firmly established today. A question is whether it would be desirable and practically feasible to favour the use of primary, secondary and tertiary language on a more regular basis in SLA and TLA usage as the full terms for which L1, L2 and L3 are the short forms.

\section{References}

Aronin, L. and Singleton, D. 2012. Multilingualism. Amsterdam: John Benjamins.

Bardel, C. and Falk, Y. 2007. The role of the second language in third language acquisition: The case of Germanic syntax. Second Language Research 23: 459-484.

Bardel, C. and Falk, Y. 2012. The L2 status factor and the declarative/procedural distinction. In Third Language Acquisition in Adulthood, Cabrelli Amaro, J., Flynn, S. and Rothman, J. (eds.), 61-78. Amsterdam: John Benjamins.

Bardel, C. and Lindqvist, C. 2007. The role of proficiency and psychotypology in lexical cross-linguistic influende: A study of a multilingual learner of Italian L3. In Atti del VI Congresso di Studi dell'Assoziatione Italiana di Linguistica Applicata, Napoli 9-10

February 2006, Chini, M., Desideri, P., Favilla, M.E. and Pallotti G. (eds.), 123-145. Perugia: Guerra Editore. 
Bardel, C., Falk, Y. and Lindqvist, C. 2013. Multilingualism in Sweden. In Current Multilingualism: A New Linguistic Dispensation, Singleton D., Fishman J. A., Aronin L. and M. Ó Laoire (eds.), 247-269. Boston and Berlin: De Gruyter Mouton.

Blommaert, J. and Backus, A. 2013. Superdiverse repertoires and the individual. In Multilingualism and Multimodality: Current Challenges for Educational Studies, de SaintGeorges, I. and Weber, J.-J. (eds.), 11-32. Rotterdam: Sense Publishers.

Boix-Fuster, E. (ed.). 2015. Urban Diversities and Language Policies in Medium-Sized Linguistic Communities. Bristol: Multilingual Matters.

Bybee, J. L. and Beckner, C. 2012. Usage-based theory. In The Oxford Handbook of Linguistic Analysis, Heine, B. and Narrog, H. (eds), Oxford: Oxford University Press.

Cenoz, J. 2001. The effect of linguistic distance, L2 status and age on cross-linguistic influence in third language acquisition. In Cross-linguistic Influence in Third Language Acquisition: Psycholinguistic Perspectives, Cenoz J., Hufeisen, B. and Jessner, U. (eds.) Clevedon: Multilingual Matters, 8-20.

Cenoz, J. 2003. The additive effect of bilingualism on third language acquisition: A review. International Journal of Bilingualism 7: 71-87.

Cenoz, J. 2013. The influence of bilingualism on third language acquisition: Focus on multilingualism. Language Teaching 46: 71-86.

Cenoz, J. and Jessner, U. (eds). 2000. English in Europe: The Acquisition of a Third Language. Clevedon: Multilingual Matters.

Cook, V. J. 1992. Evidence for multicompetence. Language Learning 42: 557-591.

De Angelis, G. 2005. Multilingualism and non-native lexical transfer: an identification problem. International Journal of Multlilingualism 2: 1-25.

de Bot, K. 2004. The multilingual lexicon: Modelling selection and control, International Journal of Multilingualism 1: 17-32. 
Delsing, L.-O. and Lundin Åkesson, K. 2005. Håller språket ihop Norden? En forskningsrapport om ungdomars förståelse av danska, svenska och norska. (TemaNord 2005:573.) Copenhagen: Nordiska ministerrådet.

Ellis, N. C. and Larsen-Freeman, D. (eds). 2009. Language as a Complex Adaptive System. (Language Learning 59, Supplement.)

Extra, G. 2015. Mapping urban multilingualismin Europe: In search of untapped resources in primary schools. In Urban Diversities and Language Policies in Medium-Sized Linguistic Communities, Boix-Fuster, E. (ed.), 1-24. Bristol: Multilingual Matters.

Extra, G. and Gorter, D. (eds.). 2001. The other languages of europe:Demographic, sociolinguistic and educational perspectives. Clevedon: Multilingual Matters.

Extra, G. and Gorter, D. (eds.). 2008. Multilingual Europe: Facts and Policies. Berlin: Mouton de Gruyter.

Extra, G. and Yağmur, K. (eds.). 2004. Urban Multilingualism in Europe : Immigrant Minority Languages at Home and School. Clevedon: Multilingual Matters.

Falk, Y. 2015. Lexical transfer in L3 learning: A cross-sectional study on Swedish.In Learning and Using Multiple Languages: Current Findings from Research on Multilingualism, Safont Jordà, M.P. and Portolés, L. (eds.), 155-173. Newcastle upon Tyne: Cambridge Scholars Publishing.

Falk, Y. and Bardel, C. 2010. The study of the role of the background languages in third language acquisition. The state of the art. IRAL, International Review of Applied Linguistics in Language Teaching 48: 185-220.

Falk, Y. and Bardel, C. 2011. Object pronouns in German L3 syntax: Evidence for the L2 status factor. Second Language Research 27: 59-82.

Green, David W. 1986. Control, activation and resource: a framework and a model for the control of speech in bilinguals. Brain and Language 27: 210-223. 
Green, David. 1998. Mental control of the bilingual lexico-semantic system. Bilingualism: Language and Cognition 1: 67-81.

Gumperz, J. J. 1972. Introduction. In Directions in Sociolinguistics: The ethnography of communication, J. J. Gumperz and Hymes, D. (eds.), 1-25. New York: Holt, Rinehart and Winston.

Hammarberg, B. 2010. The languages of the multilingual: Some conceptual and terminological issues. IRAL, International Review of Applied Linguistics in Language Teaching 48: 91-104.

Hammarberg, B. 2012. Third language acquisition. In The Routledge Encyclopedia of Second Language Acquisition, Robinson, P. (ed.), 644-648. London: Routledge.

Hammarberg, B. in press. Becoming multilingual: The macro and the micro time perspective. To appear in IRAL.

Hammarberg, Bj. and Hammarberg, Br. 2009. Re-setting the basis of articulation in the acquisition of new languages: A third language case study. In Processes in Third Language Acquisition, B. Hammarberg (ed.), pp. 74-85. Edinburgh: Edinburgh University Press.

Hammarberg, B. and Williams, S. 2009. A study of third language acquisition. In Processes in Third Language Acquisition, B. Hammarberg (ed.), 17-27. Edinburgh: Edinburgh University Press.

Heine, L. 2002. Der Einfluss vorher gelernter Sprachen auf das aktuelle Sprachenlernen. Ergebnisse einer empirischen Studie. Paper presented at the Second International Conference on Third Language Acquisition and Trilingualism, Fryske Akademy, 13-15 September 2001, in Interactive CD-ROM, L3 Conference, M. Hooghiemstra (ed.) Ljouwert/Leeuwarden: Fryske Akademy.

House, J. 2008. English as lingua franca in Europe today. In Multilingual Europe: Facts and Policies, Extra, G. and Gorter, D. (eds.), 63-85. Berlin: Mouton de Gruyter. 
Hufeisen, B. 1998. L3 - Stand der Forschung - Was bleibt zu tun? In Tertiärsprachen: Theorien, Modelle, Methoden, Hufeisen, B. and Lindemann, B. (eds). Tübingen: Stauffenburg Verlag.

Hufeisen, B. 2003. L1, L2, L3, L4, Lx - alle gleich? Linguistische, lernerinterne und lernerexterne Faktoren in Modellen zum multiplen Spracherwerb. Zeitschrift für interkulturellen Fremdsprachenunterricht 8: 1-13.

Hufeisen, B. 2005. Multilingualism: Linguistic models and related issues. In Hufeisen, B. and Fouser, R. J. (eds.), Introductory Readings in L3, 31-45. Tübingen: Stauffenburg Verlag.

Hufeisen, B. 2010. Theoretische Fundierung multiplen Sprachenlernens - Faktorenmodell 2.0. Jahrbuch Deutsch als Fremdsprache 36: 200-207.

Hufeisen, B. and Lindemann (eds), B. 1998. Tertiärsprachen: Theorien, Modelle, Methoden. Tübingen: Stauffenburg Verlag.

Hufeisen, B. and Marx, N. 2007. How can DaFnE and EuroComGerm contribute to the concept of receptive multilingualism? In Receptive Multilingualism: Linguistic Analyses, Language Policies, and Didactic Concepts, ten Thije, J. D. and Zeevaert, L. (eds.), Amsterdam: John Benjamins.

Hyltenstam, K. and Abrahamsson, N. 2003. Maturational constraints in SLA. In The Handbook of Second Language Acquisition, Doughty C.J. and Long, M. H. (eds.), 539-588. Malden MA and Oxford.

Kellerman, E. 1977. Toward a characterization of the strategy of transfer in second language learning. Interlanguage Studies Bulletin 2: 58-145.

Kellerman, E. 1978. Giving learners a break: native language intuitions as a source of predictions about transferability. Working Papers on Bilingualism 15: 59-92. 
Kellerman, E. 1983. Now you see it, now you don't. In Language Transfer in Language Learning, Gass, S. and Selinker, L. (eds.) , 112-134. Rowley MA: Newbury House.

Klein, H. G. and Rutke, D. (eds.). 2004. Neuere Forschungen zur europäischen Interkomprehension. Aachen: Shaker Verlag.

Källström, R. and Lindberg, I. 2011. Young Urban Swedish: Variation and Change in Multilingual Settings. (Göteborgsstudier i nordisk språkvetenskap 14.) Göteborg: Göteborgs universitet, Institutionen för svenska språket.

Langacker, R. W. 1999. A dynamic usage-based model. In Usage-based models of language, Barlow, M. and Kemmer, S. (eds), 1-63. Stanford, CA: CSLI Publications.

Larsen-Freeman, D. and Cameron, L. 2008. Complex Systems and Applied Linguistics. Oxford: Oxford University Press.

Lindqvist, C. 2010. Inter- and intralingual lexical influence in advanced learners' French L3 oral production. IRAL, International Review of Applied Linguistics in Language Teaching 48: $131-157$.

Lindqvist, C. and Falk, Y. 2014. When Germans begin to learn Swedish: Which is the transfer source for function words, content words and syntax? EUROSLA Yearbook 14: 225-239.

Llama, R., Cardoso, W. and Collins, L. 2010. The influence of language distance and language status on the acquisition of L3 phonology. International Journal of Multilingualism 7: 39-57.

McLaughlin, B. 1984. Second-Language Acquisition in Childhood. Volume 1. Preschool Children. $2^{\text {nd }}$ edn. Hillsdale, NJ and London: Lawrence Erlbaum Associates.

Meisel, J. 1983. Transfer as a second language strategy. Language and Communication 3: 1146.

Meisel, J. M. 2011. First and Second Language Acquisition. Cambridge: Cambridge University Press. 
Neuner, G. 2004. The concept of plurilingualism and tertiary language didactics. In The Pluralism Project: Tertiary Language Learning - German after English, Hufeisen, B. and Neuner, G. (eds), 13-34. Strasbourg: Council of Europe Publishing.

Ó Laoire, M. and Singleton, D. 2009. The role of prior knowledge in L3 learning and use: Further evidence of psychotypologuical dimensions. In The exploration of multilingualism: Development of research on L3, multilingualism and multiple language acquisition, Aronin, L. and Hufeisen, B. (eds), 79-102. Amsterdam: John Benjamins.

Paradis, M. 1981. Neurolinguistic organization of a bilingual's two languages, in The Seventh LACUS Forum, Copeland, J. E. and Davis, P. W. (eds), 486-494. Columbia, SC: Hornbeam Press.

Paradis, M. 2004. A Neurolinguistic Theory of Bilingualism. Amsterdam/ Philadelphia: John Benjamins.

Paradis, M. 2008. Language and communication disorders in multilinguals. In Handbook of the Neuroscience of Language, Stemmer B. and Whitaker H. (eds), 341-350. Amsterdam: Elsevier Science.

Paradis, M. 2009. Declarative and Procedural Determinants of Second Languages. Amsterdam: John Benjamins.

Quist, P. and Svendsen, B. A. (eds.). 2010. Multilingual urban Scandinavia: New linguistic practices. Bristol: Multilingual Matters.

Ringbom, H. 1987. The Role of the First Language in Foreign Language Learning. Clevedon: Multilingual Matters.

Ringbom, H. 2007. Cross-linguistic Similarity in Foreign Language Learning. Clevedon: Multilingual Matters. 
Rothman, J. 2010. On the typological economy of syntactic transfer: Word order and relative clause high/low attachment preference in L3 Brazilian Portuguese. IRAL, International Review of Applied Linguistics in Language Teaching 48: 245-273.

Rothman, J. 2011. L3 syntactic transfer selectivity and typological determinacy: The typological primacy model. Second Language Research 27: 107-127.

Rothman, J. and Cabrelli Amaro, J. 2010. What variables condition syntactic transfer? A look at the L3 initial state. Second Language Research 26: 189-218.

Sánchez, L. 2011. 'Luisa and Pedrito's dog will the breakfast eat': Interlanguage transfer and the role of the second language factor. In New Trends in Crosslinguistic Influence and Multilingualism Research, De Angelis, G. and Dewaele, J.-M. (eds), 86-104. Bristol: Multilingual Matters.

Verspoor, M. H., de Bot, K. and Lowie, W. 2011. A Dynamic Approach to Second Language Development: Methods and Techniques. Amsterdam: John Benjamins.

Weinreich, U. 1953. Languages in Contact: Findings and Problems. 3rd printing, 1964. The Hague: Mouton.

Williams, S. and Hammarberg, B. 2009 [1998]. Language switches in L3 production: Implications for a polyglot speaking model. In Hammarberg, B. (ed.), Processes in Third Language Acquisition, 28-73. Edinburgh: Edinburgh University Press (2009). Originally in Applied Linguistics 19: 295-333 (1998).

Wrembel, M. 2010. L2-accented speech in L3 production. International Journal of Multilingualism 7: 75-90. 